\title{
NARRATIVE ANACRUSIS: A DESCRIPTIVE ANALYSIS IN HEALTHY ADULTS SPEAKING ENGLISH
}

\author{
Balaji Rangarathnam, SreejyothiBhaskaran, R. Manjula \\ East Carolina University, Department of Communication Sciences and Disorders, 600 Moye Blvd., Mailstop \\ 668,Greenville, NC 27834. \\ Email: rangarathnamb@ecu.edu \\ AarupadaiVeedu Medical College and Hospital, Faculty of Allied Health Sciences, Puducherry, India. \\ sree.subu@gmail.com \\ All India Institute of Speech and Hearing, Department of Speech-Language Pathology, Mysore, India. \\ r.manjula@gmail.com
}

\begin{abstract}
Anacrusis is the tendency to produce one or more unstressed syllables at the beginning of an utterance in a language. Such syllables are often pronounced rapidly and strongly reduced in duration. Anacrusis has been reported extensively in music, while studies related to spoken language are sparse. This study aimed to analyze the occurrences of anacrusis in narrative speech of healthy Asian-Indian adults speaking English. This was carried out by perceptually identifying the intonation groups and to identify anacrustic and non-anacrustic occurrences with reference to the primary stress and to acoustically verify the presence of 'anacrusis' using the measure 'average syllable duration index'. Ten healthy AsianIndian adults [5 males and 5 females] within the age range of 18-25 years, proficient in English, participated in the study. The task was to narrate on a topic ("college life") for 1 minute. The samples were audio recorded and perceptually analyzed for primary stress. Further, the average syllable duration of each utterance was calculated. Results suggest that anacrusis was often noticed in the initial part of the intonation groups but there were few instances where the anacrustic segments occurred in the medial or final positions also. More identifications of primary stress were observed in the nonanacrustic utterances compared to the anacrustic utterances. Average syllable duration increased as the word position moved from first word position to the final word position in an intonation group suggesting the presence of anacrusis. The anacrustic and non-anacrustic segments in each intonation groups on an average exhibited a $1 / 3^{\text {rd }}: 2 / 3^{\text {rd }}$ representation.
\end{abstract}

\section{Indexing terms/Keywords}

Anacrusis; Intonation Group; Primary Stress

\section{Academic Discipline And Sub-Disciplines}

Applied linguistics, Speech-Language Sciences

\section{TYPE (METHOD/APPROACH)}

Exploratory analysis, descriptive methods

\section{Council for Innovative Research}

Peer Review Research Publishing System

Journal: Journal of Advances in Linguistics

Vol. 5, No. 1

editorjalonline@gmail.com

www.cirjal.com 


\section{INTRODUCTION}

Speech is uttered in real time. Speech production involves a complex interplay of prosodic, syntactic and semantic aspects coded with the motor components of the act. The influence of prosodic markers among this array of modules on spoken discourse is not as well-defined as in single words and phrases. This paper addresses discourse from the perspective of temporal rhythm, rate and stress, which in turn contribute to a phenomenon called 'Anacrusis'. Anacrusis is the tendency to produce one or more unstressed syllables at the beginning of an utterance in spoken language. Anacrusis is a feature predominantly appreciated in music where it constitutes the initial unstressed notes, described by Hermann as early as 1799 (as cited in Hermann, 1830). In connected speech, it is an important prosodic aspect in normal speech production and yet, investigations addressing the perceptual and acoustic characteristics and correlates are sparse in the literature. This study reports preliminary descriptive analysis of the feature from a perceptual and temporal standpoint in spoken utterances of adults.

Adult speakers apply generative rules to produce speech in a hierarchy of morphemes, words, phrases and sentences at a syntactic level (Langus et al., 2012). Similarly at a prosodic level, speakers apply rules in a hierarchy of syllables to the 'utterance' (Hayes, 1989). A prosodic hierarchy traditionally constitutes a phonological phrase and an intonational phrase/group that defines the natural pauses and inflections in a sentence (Pierrehumbert, 1990). Jassem (1952) defined a rhythmic unit called 'tonal unit' as an utterance or that part of an utterance which is delimited by two consecutive tonal junctures. Tonal junctures are usually seen in the beginning of an utterance after silence and during normal pauses separating utterances with specific meaning. 'Tonal units' have been used with different terminologies such as 'Intonation unit' (Di Cristo, 1998) and 'Intonation group' (Cruttenden, 1986). In her seminal work of proposing a theory for intonation, Pierrehumbert (1980) used the term 'Intonational phrase' to describe a specified sequence of phonological elements: Nuclear Pitch Accent followed by a Phrase Accent and a Boundary Tone. Several reports (e.g. Shattuck-Hufnagel\& Turk, 1996) have demonstrated that syntactic and prosodic organization are not essentially isomosphic. Therefore, it is more appropriate to discuss the prosodic features in the context of an intonation group/phrase rather than syntactically mediated sentences.

The feature of speeding of initial syllables has been reported in the literature within the context of intonation groups. For example, in a very early study by Goldman-Eisler (1968), it was demonstrated that there is a general slowing down of the articulation rate throughout an intonational phrase. That is, initial syllables are produced with faster rates and this feature was described as 'rallentando'. The rallentando pattern was further confirmed later by Dankoviccova (1997) who studied four different speakers in three different speech tasks in the Czech language. Dankovicova (1999) also reported a similar pattern in a reading task in English.

Descriptions of differences in acoustic and perceptual properties in different segments within an intonational phrase have also been reported. For example, Hirschberg \&Nakatani (1996) segmented an intonational phrase into three and reported significantly higher F0 energy characteristics for the initial segments in their text only and text-speech data. Additionally, the medial segment was significantly slower than the initial and final segments. Various other studies (Crystal \& House, 1990; Choi et al., 2005; Hirschberg, 1993; Hirschberg \&Pierrehumbert, 1986) on speech segmentation have also revealed significant differences in tune, accent and pitch range properties within different segments in an intonational phrase.

These findings warrant an understanding of anacrusis as a function of speech rate in spoken discourse. Although direct and indirect evidences exist pointing to the presence of a general tendency to utter syllables in the initial parts of an intonation group with a faster rate, more structured investigational reports are limited. Also, evidences for the presence of such a feature are not clear. For instance, the segmentation studies by Hirschberg et al.(1986), indicate higher frequency and energy in the initial segments, which by convention should indicate increased stress and therefore decreased rate of articulation. However, the features of 'ralletendo' described in studies by Dancoviccova (1997) and Dancovicova (1999) contrast this notion. It is, therefore, of interest to understand the phonetic nature of this feature, if it exists at all in normal speech. This study attempts to investigate this feature and examine its relationship with reference to the primary stress or the nuclei within the intonation group. It also attempts to explore the temporal characteristics of anacrustic and nonanacrustic utterances. Presence of anacrustic utterances in the initial syllables of speech structure may also serve as evidence for understanding the planning/programming premises of any linguistic information. In addition, the findings could be of support in speech synthesis systems and analysis paradigms of text to speech. Specifically, the study was aimed to (a) study the occurrences and features of anacrusis in narrative speech of healthy Asian-Indian adults speaking English, in the context of perceptually identified intonation groups and perceptually identified primary stress and to (b) verify the presence of the feature of 'anacrusis' using the measure 'average syllable duration index'. It was hypothesized that anacrusis as a feature will be perceived in the initial segments of an intonational phrase (the term 'intonation group' is used throughout the text from this point) and that the average syllable duration will be shorter for parts of an intonation group identified as anacrustic.

\section{METHOD}

\section{Participants}

Ten adults (5 females), from India, within the age range of 18-25 years participated in the study. Subjects were healthy individuals without any speech, language or sensory impairments. This was ensured by an informal speech-language screening by the investigators. Absence of prior history of speech, language or hearing impairments was also ensured. All the subjects were enrolled in undergraduate/graduate courses and had a minimum of 10 years of education with English 
as the medium of instruction. The first language of all the speakers was Kannada, a Dravidian language spoken in southern India. This was kept constant to control the influence of accent, articulation, use of lexical categories and other rate related variations in the speech. All the subjects demonstrated high proficiency levels in English as assessed by the Language Experience and Proficiency Questionnaire (LEAP-Q) (Marian, Blumenfeld\&Kaushanskaya, 2007). Additionally, a self-reported proficiency level of more than $90 \%$ in English was reported by all the subjects. The subjects also had a normal rate of speech as analyzed perceptually by the investigators. A spontaneous speech sample was first elicited and subjects with a rate of 150-180 words per minute were included for the study.

\section{Test Material \& Task}

The subjects were asked to narrate on the topic 'College Life' for a duration of 1 minute. The samples were collected from individual subjects and they were instructed to narrate as naturally as possible. The samples of the speakers who were extremely hesitant, had fluency breaks, repetitions and prolongations were excluded from the study. The samples were recorded using a Sony digital audio recorder in a quiet room. The samples were then subjected to analysis.

\section{Perceptual analysis}

The extracted samples were first subjected to literal transcription. Broad transcription method using standard IPA symbols was used. Intonation groups were marked using the phonetic cues suggested by Cruttenden (1986). 'Intonation groups' were identified in all the transcribed speech samples of 10 speakers by 3 judges (investigators). The syllables that were produced at a perceptually faster rate in an intonation group were identified and were defined as anacrustic utterances. The non-anacrustic syllables were defined as the remaining syllables in the intonation group i.e. those syllables, which were produced with the perceptually slower rate. The details of the analysis of the transcribed data are as follows.

\section{Identification of intonation groups and anacrustic and non-anacrustic segments}

A prosodic 'sentence' structure when spoken in a natural manner often carries punctuation markers. These punctuation markers give rise to junctures in the spoken utterance and help in dividing the spoken utterance into the smallest unit or part. These smallest units or parts of an intoned utterance constitute the intonation groups or tone groups of the utterance. Anacrusis is closely linked with the intonation groups or 'tone units' of an intonation contour. Hence the feature of anacrusis was analyzed within the context of intonation groups. During the identification of the intonation groups, the three investigators listened to the audio recorded sample in unison, sentence by sentence, repeatedly until they were satisfied about their identification of the intonation groups and achieved a minimum agreement of $90 \%$ across the speech samples.

The total number of anacrustic and non-anacrustic syllables in each intonation group of each speaker was identified. The identification was based on the perceptual judgment of the three investigators. The syllables that were uttered with an increased rate within an intonation group were identified as anacrustic utterances and those uttered with a normal rate (for the speaker concerned) within the same intonation group were identified as non-anacrustic utterances. The total number of anacrustic and non-anacrustic syllables in each intonation group in the speech sample of each speaker was calculated and tabulated.

\section{Occurrence of primary stress in the anacrustic and non-anacrustic utterances}

The prosodic feature of stress involves loudness, length and variability in pitch (Plag, Kunter\& Schramm, 2011). Often, the anacrustic utterances within an intonation group are reported to carry unstressed syllables and the non-anacrustic utterances within an intonation group are reported to carry stressed syllables (Jassem, 1952b). That is, there is a common tendency reported in the literature suggesting that it is the non-anacrustic segments in an intonation group, which are more likely to carry the stressed syllables than the anacrustic segments of the intonation group. However, not many studies are carried out in this direction to verify the perceptual notion. With this in mind, the occurrence of stressed syllables within the anacrustic and non-anacrustic segments of the intonation groups was analyzed. This was carried out through a perceptual identification task of listening to each intonation group of each of the speaker's utterance by the three investigators. The identifications were later checked for mutual agreement by the three judges and in instances of disagreement, the procedure was repeated until the stressed syllables were identified and mutually agreed upon. For identification of stressed syllables, the judges depended on cues related to any change in the form of increase or decrease in the duration, loudness and pitch of the syllable and the semantic and syntactic contextual clues. The total number and instances of occurrences of stressed syllables with reference to the anacrustic and non-anacrustic segments in the intonation groups was calculated and tabulated. A scatter plot was plotted with syllable length (within the intonation group) in the horizontal axis and occurrence of primary stress in the anacrustic and non-anacrustic segments in the vertical axis.

The raw data in the form of (a) total number of syllables in the anacrustic and non-anacrustic segments of the intonation group and (b) instances of occurrences of stressed syllables with reference to the anacrustic and non-anacrustic segments of the intonation groups was perceptually analyzed.

\section{Temporal analysis:}

Verification of the occurrence of 'anacrusis' with a measure of average syllable duration index.The perceptually identified intonation groups were subjected to analysis of durational aspects using the 'PRAAT software' (Boersma\&Weenink, 2005). The samples were digitized at a sampling frequency of $16 \mathrm{KHz}$ and 8-bit quantization. The duration of each word was computed and the 'average syllable duration index' was obtained. 'The average syllable 
duration index' was defined as the ratio of the word duration to the number of syllables in the word. The corpus data thus generated were grouped based on the number of words in an intonation group. The mean was calculated for each group and comparisons across the gender and the word length were attempted for all subjects.

\section{RESULTS AND DISCUSSION}

The study was carried out to analyze the specific features and occurrence pattern of the feature of 'anacrusis' in the narrative mode for English speaking healthy individuals in India. The initial analysis process was perceptual and this was later complemented with the acoustic analysis of duration of syllables.

\section{Total number of syllables in the anacrustic and non-anacrustic segments of the intonation group}

The total number of syllables in the anacrustic and non-anacrustic segments of the intonation groups of each speaker was identified. The group total and mean were obtained and this is represented in Table 1.

In the 194 intonation groups identified, the total number of syllables identified was 2896, of which the anacrustic syllables were approximately 1054 which amounts to $34 \%$ of the total utterances. The remaining $66 \%$ of the utterances (i.e. 1842 ) syllables were identified to be non-anacrustic.

By definition anacrusis is a feature occurring in the initial part of the utterances and in the data, this notion was supported perceptually. In the majority of instances, it was found that the increased rate of utterances of syllables, that is the feature of 'anacrusis' was often noticed in the initial part of the intonation groups but there were few instances where the anacrustic segments occurred in the medial or final positions. Further, the anacrustic elements constituted about one-third of the total number of syllables in the intonation group and the rest of the two-thirds was non-anacrustic syllables.

Table 1: Number of syllables in the Anacrustic and Non Anacrustic segments

* Each Intonation group was identified for anacrustic and non-anacrustic segments

\begin{tabular}{|c|c|c|c|c|c|c|}
\hline & $\begin{array}{l}\text { Number } \\
\text { Intonation } \\
\text { groups }^{*}\end{array}$ & of & $\begin{array}{c}\text { Total } \\
\text { number of } \\
\text { Syllables }\end{array}$ & $\begin{array}{l}\text { Mean number of } \\
\text { syllables per } \\
\text { speaker }\end{array}$ & $\begin{array}{c}\% \\
\text { Mean }\end{array}$ & $\begin{array}{l}\text { Standard } \\
\text { deviation }\end{array}$ \\
\hline $\begin{array}{l}\text { Anacrustic } \quad \text { segments } \\
\text { within intonation groups }\end{array}$ & \multirow[b]{3}{*}{194} & & 1054 & 105.4 & 34 & 1.87 \\
\hline $\begin{array}{l}\text { Non-anacrustic segments } \\
\text { within intonation groups }\end{array}$ & & & 1842 & 184.2 & 66 & 4.36 \\
\hline Total Intonation groups & & & 2896 & 289.6 & 100 & 6.23 \\
\hline
\end{tabular}

\section{Occurrence of primary stress in the anacrustic and non-anacrustic syllables:}

Scatter plots were plotted to determine the relationship between the primary stress and anacrusis. Figures $1 \& 2$ depict the scatter plot that was manually plotted to represent the distribution and placement of the perceptually identified primary stress in the anacrustic and non-anacrustic segments of the utterances of speakers with varying syllable length.

It can be inferred from the scatter plot in Figure 2 that the stressed syllables were concentrated more towards the final part of the non-anacrustic utterances and to a lesser extent towards the initial and medial portions. Further, more identifications of primary stress are observed in the non-anacrustic utterances compared to the anacrustic utterances. An overview and examination of the transcribed data revealed that the stress occurrences coincided with the content words in these positions in most of the instances. It is, however, observed that primary stress identifications have occurred in the anacrustic segments of the utterances too. Within the anacrustic segments, the primary stress has often occurred on the first few initial syllables of the words in the utterances. 


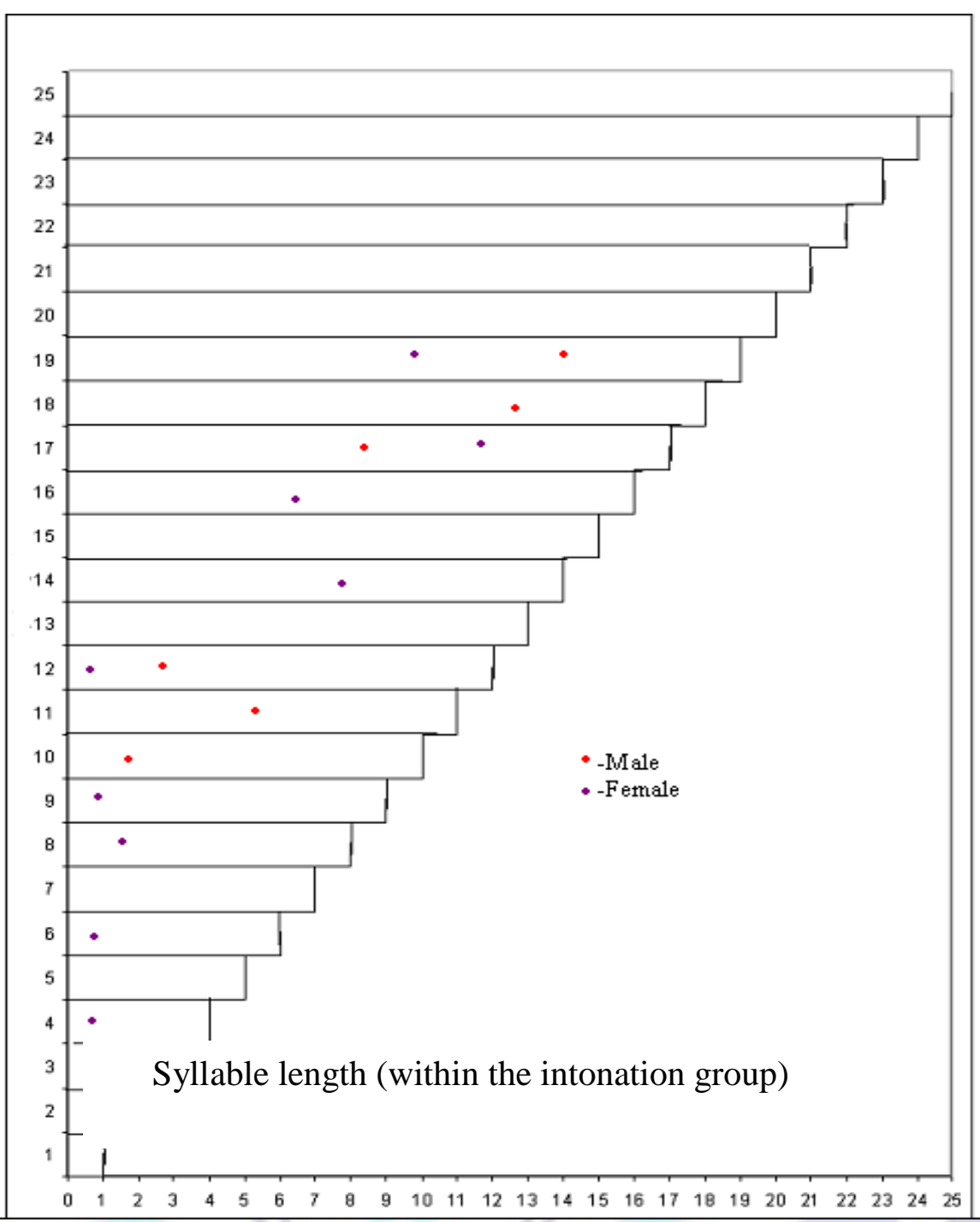

Figure. 1: Occurrence of primary stress in the anacrustic segments within the intonation group 


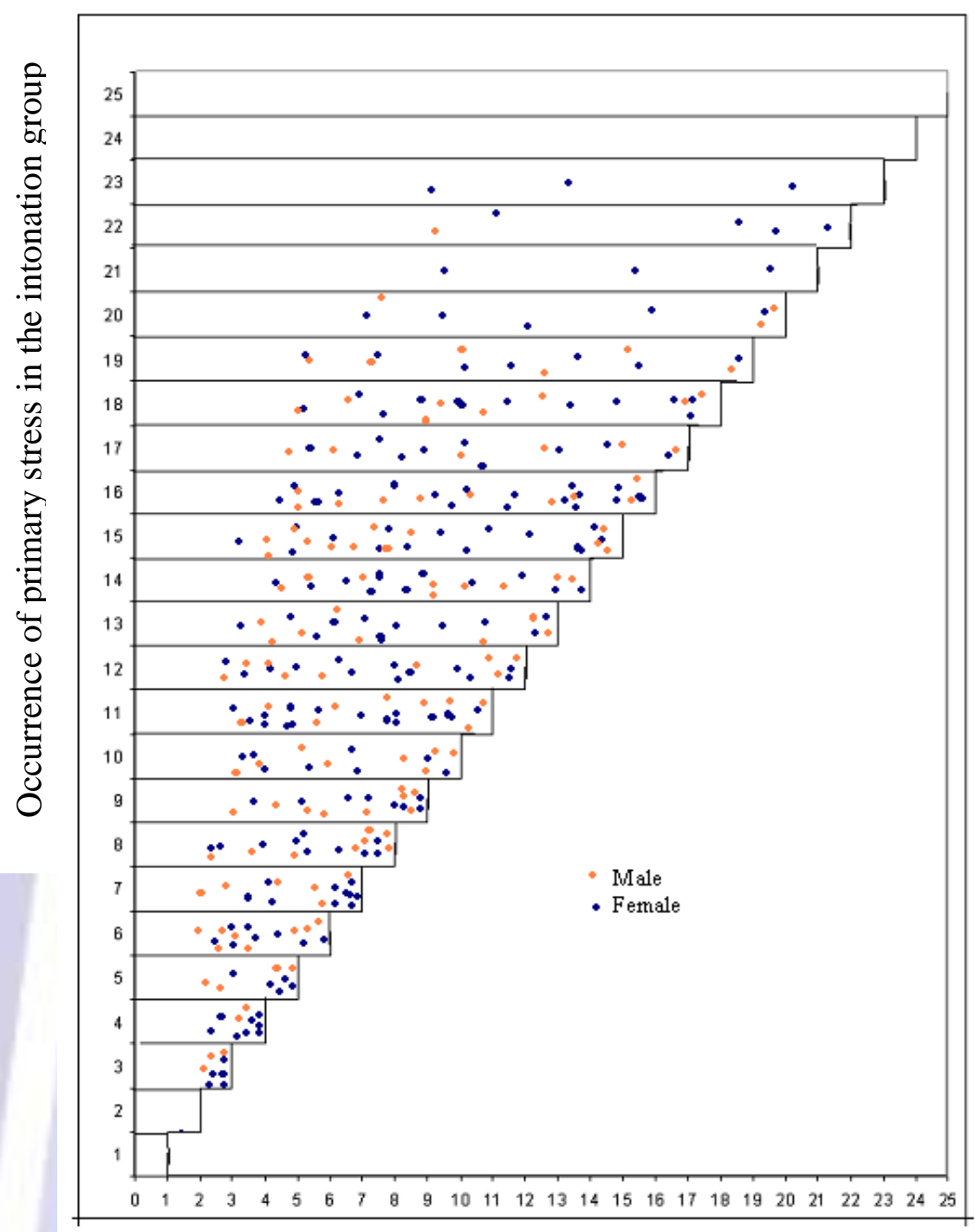

Syllable length (within the intonation group)

Figure 2: Occurrence of Primary stress in the non anacrustic segments within the intonation group

In summary, a distinct pattern seems to be evident in the placement of primary stress with reference to the anacrustic and non-anacrustic segments of the utterances. However, generalization of the statement needs to be done with care as there is need to verify this observation with a large sample.

\section{Verification of the presence of 'anacrusis' using the measure 'average syllable duration' index:}

The average syllable duration index was calculated for each word in all the intonation groups. The average syllable duration index is operationally defined in this study as the ratio of the duration of the word and the number of syllables in that particular word. The total intonation groups for all subjects were clustered on the basis of number of words in them. The summary of number of intonation groups in each word length is illustrated in Table 2. 
Table 2: The of number intonation groups for each word length in both male and female subjects

\begin{tabular}{|c|c|c|c|c|c|c|c|c|c|c|c|c|}
\hline \multicolumn{12}{|c|}{ Word length (No. of words in an intonation group) } & \multirow{2}{*}{$\begin{array}{l}\text { Total of } \\
\text { intonation } \\
\text { groups }\end{array}$} \\
\hline & 2 & 3 & 4 & 5 & 6 & 7 & 8 & 9 & 10 & 11 & 12 & \\
\hline Males & 1 & 16 & 15 & 20 & 13 & 13 & 4 & 4 & 0 & 1 & 0 & 87 \\
\hline Females & 4 & 15 & 11 & 18 & 17 & 10 & 5 & 7 & 7 & 0 & 3 & 97 \\
\hline
\end{tabular}

The variations in the average syllable duration index across these clusters were compared and graphically represented. The figures 4 to 7 depict the pattern of the average syllable duration index variation for male and female speakers across word length (Figure 3 and 5 - up to 6 words in an intonation group in male and female speakers respectively and Figure 4 and 6 - up to 12 words in an intonation group for male and female speakers across word length).

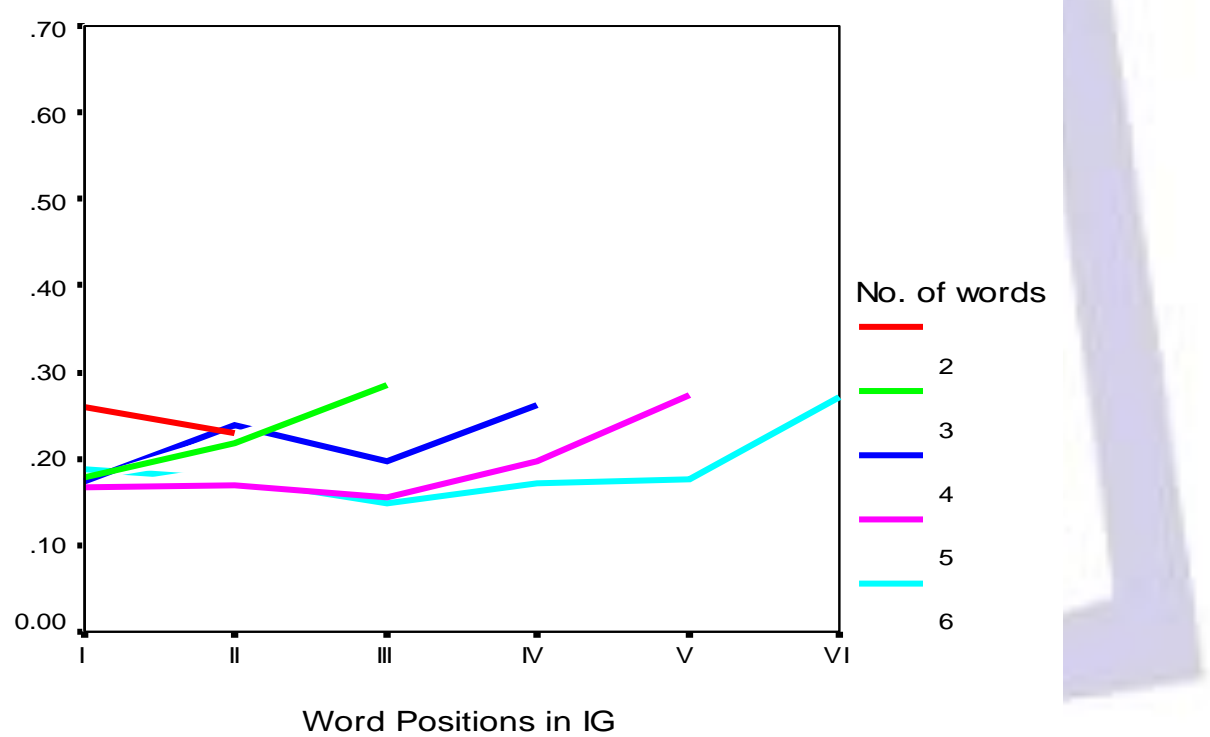

Figure 3: Representation of mean syllable duration (in sec) across word position in the intonation groups (up to a maximum of 6 words in an intonation group) in male speakers 


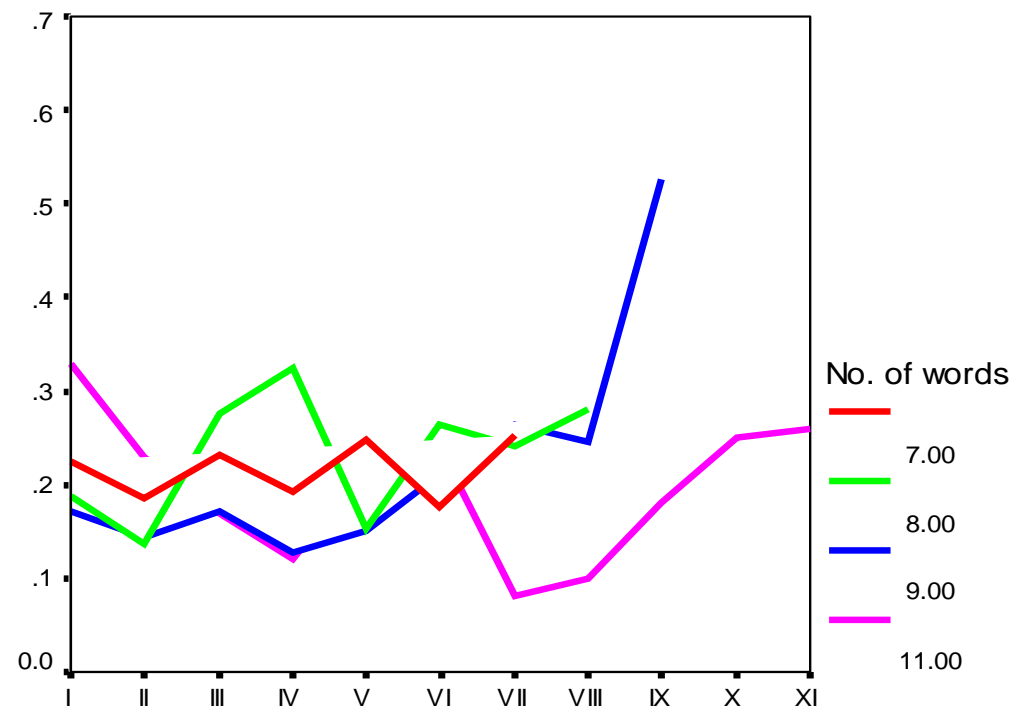

Word Positions in IG

Figure 4: Representation of mean syllable duration (in sec) across word position in the intonation groups (up to a maximum of 11 words in an intonation group) in male speakers

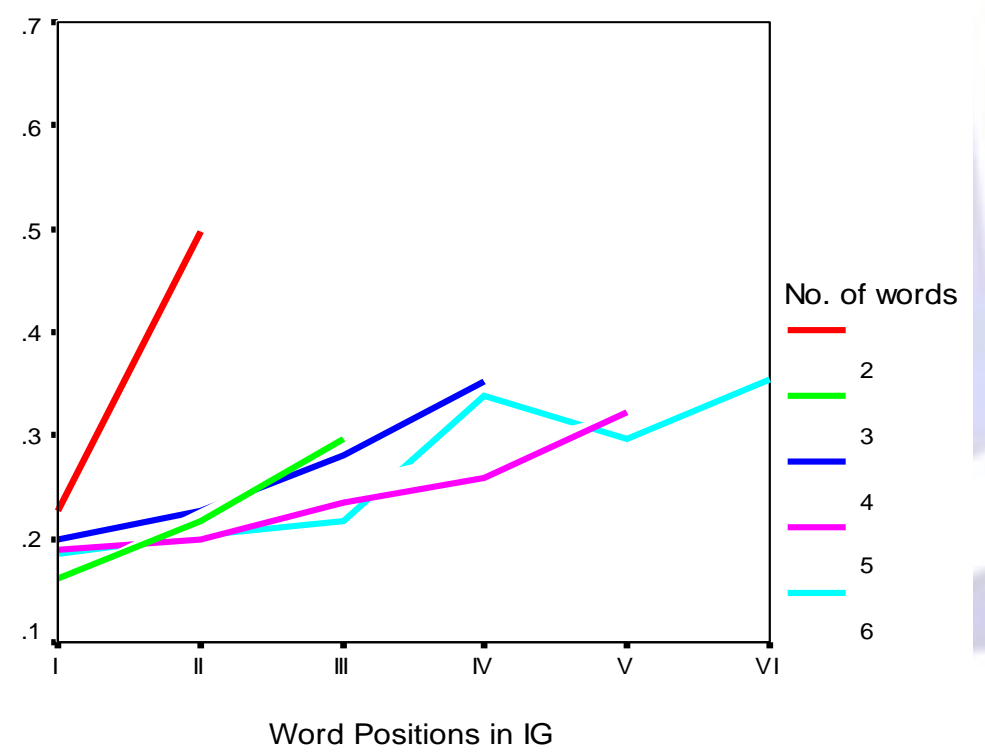

Figure 5: Representation of mean syllable duration (in sec) across word position in the intonation groups (up to a maximum of 6 words) in female speakers. 


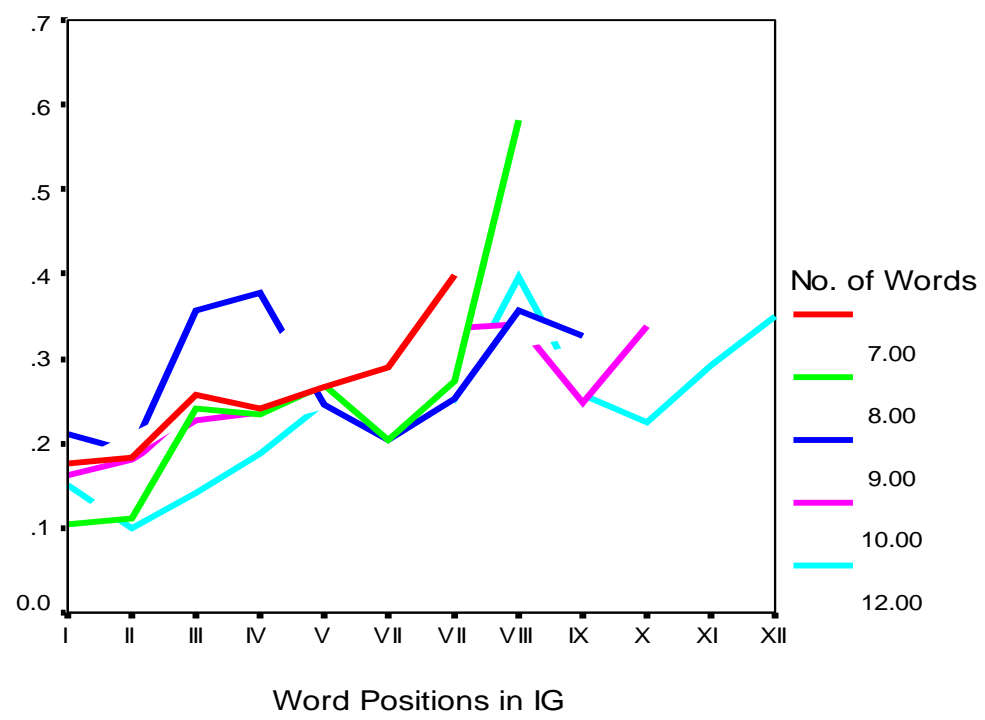

Figure 6: Representation of mean syllable duration (in sec) across word position in the intonation groups (up to a maximum of 12 words) in female speakers.

The results in Figures 3 to 6 , point to the fact that the average syllable duration increases as the word order increases from first to last portion in an intonation group. The pattern of variation in the average syllable duration, apparent in the figures suggests that there is a gradual reduction in the duration in the first 3-4 syllables or two to three words followed by an increase in the average syllable duration for the rest of the utterance across the word order (number of words in the intonation group). The reasons for a decrease in duration for the initial few syllables suggest that the utterances were produced at a faster rate implying the presence of anacrusis. Such an anacrustic pattern was clearly evident for intonation groups which had words lesser than 2-6 syllables than the intonation groups which had words greater than seven. Such a difference might be attributed to the content of narration/ selection of words and the stylistic variation incorporated by the individual, which is clearer in the longer utterances. Another striking feature evident was the steep inclination at the final position for all the intonation groups which could be addressed as a function of final syllable lengthening at the end of an intonation group (Smith, 2002). The results of the study support definite final syllable lengthening effect in the utterances of all the speakers. The findings on the anacrustic phenomenon could have important bearing in the understanding of dysfluent speech. It is quite possible that anacrusis could serve as a measure in understanding the speech motor control aspects in dysfluent speech. Future studies are however warranted to support the results of the study.

It can also be observed that for the female speakers the average syllable duration (Figures 5 and 6 ) increased in steeper fashion from word initial to word final position for utterances up to about 6 words in an intonation group and for utterances greater than 6 words a declination in duration for about 2-3 words was evident. This well supports the perceptual evidence of anacrusis. Declination in duration at the other positions refutes the localization of anacrusis in the initial position of the intonation group. This statement is made with the limitations that more data and an in depth study of the relational analysis of the occurrence patterns of pauses and stressed syllables was not undertaken in the study. Also, the index used in the study i.e. the average syllable duration index may have to be supplemented with other measures such as phoneme duration or frequency and intensity measures to arrive at more definite conclusions.

In summary, theoccurrence of the anacrustic utterances was perceptually seen in the initial part of the intonation group. The data points to the fact that anacrusis is a feature that is witnessed in healthy speakers in a narration mode. It is possible that similar trends may be seen for reading and conversation patterns, but this needs to be explored with further studies. As to the reason for the occurrence of anacrusis, further studies are required in order to understand in terms of the cognitive linguistic substrate in the neural processing, the speech motor control in terms of planning and sequencing in the phonological buffer and the contribution of sensory and proprioceptive feedback in controlling and modulating this phenomenon. Postulation at this point of time with the existing data would be premature and incomplete. It is however, intriguing to observe that there is a definite pattern seen in terms of the proportion of the anacrustic and non-anacrustic segments (36\%:64\%) when intonation groups are considered as the basic units. Further there seems to be a definite pattern in terms of the occurrence of primary stress on syllables in the anacrustic and non-anacrustic segments as shown in Figure 1.

\section{CONCLUSION}

The preliminary data suggests that anacrusis was observed as a phenomenon in the narrative speech of all speakers. There seems to be a clear distribution pattern, in that when intonation groups were considered as basal units, the anacrustic and non-anacrustic segments in each intonation group on an average exhibited a $1 / 3^{\text {rd. }}: 2 / 3^{\text {rd }}$ representation. Within this distribution, the stressed syllables were concentrated in the initial syllables of the anacrustic and the initial, 
medial and terminal syllables in the non-anacrustic segments. The temporal measure, average syllable duration showed a clear declination in duration for shorter utterance length supporting the existence of anacrusis but for the longer utterances the pattern was variable. This leads to the question as to whether the locus of an anacrustic segment is always restricted to the initial position or if there is a variability. Further studies are therefore warranted to substantiate, support and elaborate the results observed in the study.

\section{REFERENCES}

1) Hermann, G., 1830. Hermann's elements of the doctrine of metres: abridged and translated into English. AJ Valpy, Red Lion Court, Fleet Street. Sold by Longman and Company; Baldwin and Craddock;[and 3 others] Oxford; Deightons, Barrett, and Newby, Cambridge.

2) Langus, A., Marchetto, E., Bion, R.A.H., Nespor, M., 2012. Can prosody be used to discover hierarchical structure in continuous speech? Journal of Memory and Language 66, 285-306.

3) Hayes, B., 1989. The prosodic hierarchy in meter. Phonetics and phonology 1, 201-260.

4) Pierrehumbert, J., 1990. The Meaning of Intonational Contours in the Interpretation of Discourse Janet Pierrehumbert and Julia Hirschberg. Intentions in communications, 271.

5) Jassem, W., 1952. Stress in modern English. Bulletin de la SociétéLinguistique Polonaise 12, 189-194.

6) Di Cristo, A., 1998. Intonation in French. Intonation systems: A survey of twenty languages, 195-218.

7) Cruttenden, A., 1986. Intonation. Cambridge University Press, Cambridge.

8) Pierrehumbert, J.B., 1980. The phonology and phonetics of English intonation. Massachusetts Institute of Technology.

9) Shattuck-Hufnagel, S., Turk, A.E., 1996. A prosody tutorial for investigators of auditory sentence processing. Journal of psycholinguistic research 25, 193-247.

10) Eisler, F.G., 1968. Psycholinguistics: Experiments in spontaneous speech. Academic Press New York.

11) Dankovičcová, J., 1997. The domain of articulation rate variation in Czech. Journal of Phonetics 25, $287-312$.

12) Dankovičová, J., 1999. Articulation rate variation within the intonation phrase in Czech and English. age 2, 2.

13) Hirschberg, J., Nakatani, C.H., 1996. A prosodic analysis of discourse segments in direction-giving monologues. Proceedings of the 34th annual meeting on Association for Computational Linguistics. Association for Computational Linguistics, pp. 286-293.

14) Crystal, T.H., House, A.S., 1990. Articulation rate and the duration of syllables and stress groups in connected speech. The Journal of the Acoustical Society of America 88, 101.

15) Choi, J.-Y., Hasegawa-Johnson, M., Cole, J., 2005. Finding intonational boundaries using acoustic cues related to the voice source. The Journal of the Acoustical Society of America 118, 2579.

16) Hirschberg, J., 1993. Pitch accent in context predicting intonational prominence from text. Artificial Intelligence 63, 305-340.

17) Hirschberg, J., Pierrehumbert, J., 1986. The intonational structuring of discourse. Proceedings of the 24th annual meeting on Association for Computational Linguistics. Association for Computational Linguistics, pp. 136-144.

18) Marian, V., Blumenfeld, H.K., Kaushanskaya, M., 2007. The Language Experience and Proficiency Questionnaire (LEAP-Q): Assessing language profiles in bilinguals and multilinguals. Journal of Speech, Language and Hearing Research 50, 940.

19) Plag, I., Kunter, G., Schramm, M. 2011. Acoustic correlates of primary and secondary stress in North American English. Journal of Phonetics, 39(3), 362-374.

20) Boersma, P., Weenink, D., 2005. Praat: doing phonetics by computer (Version 4.3.01) [Computer program]. Retrieved from http://www.praat.org/

21) Smith, B.L., 2002. Effects of speaking rate on temporal patterns of English. Phonetica 59, 232-244. 